\title{
Managing geese with recreational hunters?
}

\author{
James Henty Williams, Thorsten J. S. Balsby, Helle Ørsted Nielsen, \\ Tommy Asferg, Jesper Madsen
}

Received: 2 November 2017/Revised: 31 May 2018/Accepted: 14 June 2018/Published online: 3 July 2018

\begin{abstract}
As many goose populations across the northern Hemisphere continue to rise, the role of hunters to manage these populations is increasingly being considered. We studied recreational goose hunters in Denmark to assess their behavioural and motivational characteristics, willingness to alter their hunting effort, as well as their ability to act as stewards of a rapidly increasing goose population. We identified several behavioural characteristics that typify effective goose hunting practices. We suggest a degree of specialization is necessary to increase goose harvests, as well as mitigating animal welfare issues (e.g. wounding). However, the majority of Danish goose hunters can be considered to be casual participants in this form of hunting. This poses a challenge for wildlife managers wishing to engage recreational hunters to manage highly dynamic wildlife populations, such as geese. If recreational hunters are to be used as a management tool, wildlife managers and hunting organizations will need to consider how best to facilitate skill development, hunting practices and socially legitimate hunting ethics to foster the stewardship role of hunting. We conclude that it is incumbent on wildlife managers to recognize and deal with both internal factors (e.g. skill development) and external influences (e.g. animal welfare concerns). In doing so, potential tensions in the multi-functionality of hunting can be alleviated, maintain hunting as a legitimate and accepted recreational past-time and management tool.
\end{abstract}

Keywords Adaptive management - Behaviours . Geese $\cdot$ Harvest management $\cdot$ Hunters $\cdot$ Motivations

Electronic supplementary material The online version of this article (https://doi.org/10.1007/s13280-018-1070-7) contains supplementary material, which is available to authorized users.

\section{INTRODUCTION}

Several goose populations in Europe have grown dramatically in size since the 1960s. These populations are increasingly the cause of conflicts with agricultural interests as well as posing threats to air safety, human and animal health and potentially detrimental effects on vulnerable ecosystems (e.g. arctic tundra) (Fox and Madsen 2017). Progressively the management of problematic goose species is being considered at a population level, employing adaptive harvest management (AHM) and requiring national and international coordination (Stroud et al. 2017). In Europe, the use of hunters and lethal control to manage problem situations involving geese has been limited and predominately confined to local schemes that are highly regulated (e.g. requiring dispensations) (Bradbeer et al. 2017; McKenzie and Shaw 2017). However, in 2012 the Svalbard population of the pink-footed goose (Anser brachyrhynchus) was chosen as the first European test case for the development of an International Species Management Plan (ISMP) (Madsen and Williams 2012). This management plan included setting a population target as part of a series of objectives and management actions, instigated to reduce agricultural conflicts and avoid tundra degradation (Madsen et al. 2017). To maintain a stable population size, an AHM strategy was developed using recreational hunting. The initial aim of the AHM strategy was to reduce the population to an agreed level of 60000 birds, requiring its reduction from a peak of 80000 (the estimated population size in 2013).

The use of hunting to manage a population shifted the emphasis of hunting as a recreational pastime to that of a management tool as part of a structured adaptive management framework. Hunting has multiple roles in contemporary society that span socio-cultural (e.g. recreation, 
identity, food and trophies), ecological (e.g. wildlife management) and economic functions (e.g. crop protection) (Fischer et al. 2013b). Tensions can arise between these functions of hunting, particularly if functions (e.g. economic) intended by wildlife managers are at odds with those accepted by society and its various constituent communities (e.g. recreational hunters). The acceptance of hunting as an activity as well as its use as a management tool is dependent on perceptions of why and how it is practised. Negative attitudes towards hunting can emerge if it is perceived as excessive or where the motives for hunting are perceived as simply for the sake of killing or excitement, rather than satisfying existential needs (e.g. providing food) or providing a valued service (e.g. ecological benefits) (Fischer et al. 2013a; Gamborg and Jensen 2017). Furthermore, hunters themselves have their own codes of conduct, taboos and motives that guide acceptable hunting practices (von Essen 2018). The motives of recreational hunters have been well studied for a variety of hunting types, revealing multiple motives (e.g. those seeking a nature experience, gaining food, for excitement, skill development and social bonding) (Decker and Connelly 1989; Schroeder et al. 2006; Radder and Bech-Larsen 2008). It is also evident, particularly in Scandinavian countries, that although hunters may hunt for self-fulfilment there are other rationale claimed for their pastime. Many hunters consider hunting as having a beneficial role in the sustainable management and care of wildlife and regard themselves as responsible stewards (Kaltenborn et al. 2013; Gamborg et al. 2017).

In our study, it was recognized that desired outcomes of the AHM strategy were very much dependent on the willing participation of recreational hunters. The plan was dependant on the interest and acceptance by hunters to, initially, shoot more geese (Madsen et al. 2017). However, detailed knowledge was lacking about basic hunting behaviours and motivations of recreational goose hunters in Denmark, who shot the majority (ca 80\%) of pink-footed geese (Madsen et al. 2017). Denmark and Norway are the only two countries along the flyway where hunting them is permitted. We focused our attention on this community of hunters to gain a better understanding of the characteristics of different segments, as well as the potential of these segments to play an active and willing part in the management of a goose population. Initial analysis indicated that there were marked differences in annual bag sizes and we opted to create exploratory hunter groups based on total goose bag sizes for the 2013 hunting season. Our objectives for this study were to (a) assess the hunting activity of these groups, as well as what influence/impact they correspondingly had on the Danish goose harvest; (b) determine what behavioural characteristics differentiated these groups and what enabled some hunters to achieve higher goose bags; (c) identify if there were any motivational characteristics that were indicative of these groups and (d) determine the attitudes of these groups towards managing goose populations and their willingness to modify their goose hunting activity.

\section{MATERIALS AND METHODS}

\section{Hunting bag records}

We had access to the Danish wildlife bag records (Vildtudbyttestatistik) which are collected by the Danish Environment Agency and a national database processed and maintained by DCE-Danish Centre for Environment and Energy at Aarhus University. All licensed Danish hunters are legally required to report what they have shot annually via an online reporting system. We focused our analysis on data collected for three hunting seasons from 2013 to 2015. Reporting of geese for these hunting seasons was, for the first time, at species level and provided a comprehensive dataset of species-specific hunting bag records for individual Danish hunters. Each hunter record had a unique I.D. code for analysis but personal data were anonymous. We used these hunting bag records to assess the overall goose bag and hunting activity of Danish goose hunters for the 2013-2015 hunting seasons. Binomial generalized linear models (GLM) were used to test if bag size could predict the likelihood of continuing to hunt geese or change bag size groups.

\section{Survey}

\section{Sample design}

We used stratified sampling to create three sample groups based on overall individual goose bags for the 2013 hunting season: low (1-2 geese); medium (3-10 geese) and high $(11+$ geese). Submitted goose bag records were available for 9660 hunters and were divided into the three desired sample groups. Of these, 666 hunters for each sample group were randomly selected and invited to participate in the survey. This sampling procedure was undertaken to ensure sufficient responses were gained for each sample group, in particular those shooting $11+$ geese. In total, invitation letters were sent to 1998 goose hunters, throughout Denmark. They were requested to participate and complete a questionnaire using the online survey tool, SurveyXact (https://www.surveyxact.dk). An online survey was used, as in 2012 online reporting of Danish hunting bag records had been introduced. This development led to very high (98\%) reporting rates, as renewals of annual hunting licences were dependent on hunters reporting their 
Table 1 Sample structure for Danish goose hunter survey, composed of hunters who submitted hunting bag reports and shot geese in 2013. Three sample groups based on individual overall goose bags

\begin{tabular}{llllll}
\hline Survey sample groups & Population & $\%$ population & Invited hunters & Respondents & Response rate (\%) \\
\hline Low bag group 1-2 & 5020 & 52 & 666 & 282 & 42 \\
Medium bag group 3-10 & 3490 & 36 & 666 & 345 & 52 \\
High bag group 11+ & 1150 & 12 & 666 & 335 & 50 \\
Total & 9660 & & 1998 & 962 & 48 \\
\hline
\end{tabular}

hunting bags (Asferg 2016). The survey was conducted in September 2014. Consent to participate was voluntary and was obtained by email. Participants were advised of the nature of the study and given written details of questions to be asked prior to interviews. All participants gave written informed consent to take part in the study. Anonymity and confidentiality of the interviews was guaranteed. A total of 962 hunters completed the questionnaire, with an overall response rate of $48 \%$ and a high number of respondents for each of the sample groups (Table 1).

\section{Questionnaire}

The questionnaire was based on a previous survey conducted amongst Danish hunters undertaken in 2000 (Hansen 2000). This was revised and adapted after a series of qualitative interviews carried out with 9 goose hunters conducted at their homes. The questionnaire was then tested and completed online by 6 of these goose hunters. Before and after piloting, advice from hunting experts was also sought. For this study, only a selected number of questions were regarded as pertinent in order to differentiate hunters and determine characteristics that distinguished the three sample groups. The selected questions covered two broad traits of hunters that could be used to model and predict goose bag sizes: (1) goose hunting behavioural characteristics and (2) reasons for going goose hunting (motivational characteristics). All categorical questions selected had sufficient responses gained at each predictor level for analysis $(>50)$. In addition, three questions were used to assess respondent attitudes to managing goose populations and their willingness to alter their hunting activity (see Table 3 ).

\section{Predictors of annual goose bags}

The survey questions provided the source data for our predictor variables. They were selected in order to define plausible alternative hypotheses (Burnham et al. 2011) reflecting distinct behavioural and motivational characteristics that might influence goose hunting opportunities, their success and ultimately determine annual goose bag sizes. Our selection of questions and subsequent model formulations were based on information gained from a number of published studies about recreational hunter behaviours and preferences, as well as our own understanding of goose hunting in Denmark (Kaltenborn et al. 2012; Primdahl et al. 2012; Wam et al. 2013; Lundhede et al. 2015; Jensen et al. 2016). Seven survey questions were used as potential behavioural predictor variables (see Table 2). Five questions assessed respondent motivations and attitudes towards goose hunting. These were considered as potential variables indicating respondent motivations for achieving higher or lower goose bags (see Table 3). These variables were used to formulate two sets of potential models to predict annual goose bags, which we treated as a continuous response variable: (1) behavioural models and (2) combined behavioural and motivational models.

\section{Data exploration}

Prior to fitting and model selection, we undertook exploratory data analyses to check for outliers and relationships between predictor variables. Cleveland dotplots and boxplots were used to visualize outliers. Variance inflation factor (VIF) values were used to assess collinearity (Zuur et al. 2009). This initial data exploration indicated that there were a number of outliers: 7 responses were considered as improbable and excluded from our analyses (e.g. 236 geese shot in 2 days). Initial analysis of the relationship between goose bag sizes and number of goose hunting days indicated overdispersion of the data. Consequently, we used negative binomial generalized linear models (GLM) with log link functions to determine associations between the response variable and selected predictor variables (Zuur et al. 2009).

\section{Model selection and validation}

We followed the information theoretic (I-T) approach (Burnham et al. 2011) to specify and test a series of candidate models. We combined predictor variables to create a series of potential models, reflecting the hypothesized hunter characteristics that might influence goose bag sizes. We started by formulating and testing two factor candidate 
Table 2 Survey questions considered as potential behavioural predictor variables

\begin{tabular}{|c|c|c|c|}
\hline Survey question & $\begin{array}{l}\text { Response type } \\
\text { and modelled } \\
\text { levels }\end{array}$ & $\begin{array}{l}\text { Predictor } \\
\text { variable }\end{array}$ & Comments and hypothesized impact \\
\hline $\begin{array}{l}\text { Approximately how many days were you out } \\
\text { hunting and you shot geese during 2013-2014 } \\
\text { hunting season? } \\
\text { How often were you out goose hunting without } \\
\text { shooting geese in 2013-2014? }\end{array}$ & $\begin{array}{l}\text { Open numeric } \\
\text { Continuous }\end{array}$ & Days & $\begin{array}{l}\text { Two questions combined to give total number of goose hunting } \\
\text { days. Indicative of investment (time and effort) and the more } \\
\text { often out hunting increases likelihood of success and larger } \\
\text { annual goose bags }\end{array}$ \\
\hline $\begin{array}{l}\text { How many goose hunting areas do you have } \\
\text { access to, including your most often used area? }\end{array}$ & $\begin{array}{l}\text { Categorical } \\
1 \\
2 \\
3 \\
4+\end{array}$ & Areas & $\begin{array}{l}\text { Access to multiple hunting areas increases hunting } \\
\text { opportunities (right place and right time) and hence higher } \\
\text { annual goose bags }\end{array}$ \\
\hline $\begin{array}{l}\text { How often do you or your hunting partners check } \\
\text { if geese are in your hunting area? }\end{array}$ & $\begin{array}{l}\text { Categorical } \\
\text { No/not often } \\
\text { Weekly } \\
\text { Daily }\end{array}$ & Check & $\begin{array}{l}\text { Investment of time as more often hunting areas checked } \\
\text { increases success of each hunting day (greater likelihood of } \\
\text { geese in hunting area) and larger annual goose bags }\end{array}$ \\
\hline $\begin{array}{l}\text { What was the distance from your home to your } \\
\text { most often used goose hunting area in } \\
\text { 2013-2014? }\end{array}$ & $\begin{array}{l}\text { Categorical } \\
0-10 \mathrm{~km} \\
11-40 \mathrm{~km} \\
41-80 \mathrm{~km} \\
80+\mathrm{km}\end{array}$ & Distance & $\begin{array}{l}\text { Increasing distances to hunting area lessens accessibility, } \\
\text { limiting hunting opportunities and leading to smaller annual } \\
\text { goose bags }\end{array}$ \\
\hline Do you have a hunting dog? & $\begin{array}{l}\text { Categorical } \\
\text { No } \\
\text { Yes }\end{array}$ & Dog & $\begin{array}{l}\text { Ownership of one or more hunting dogs considered as } \\
\text { substantial commitment (exercising dogs), increases number } \\
\text { of days out hunting leading to greater success and higher } \\
\text { annual goose bags }\end{array}$ \\
\hline $\begin{array}{l}\text { Which hunting equipment did you use most often } \\
\text { when goose hunting in 2013-2014? }\end{array}$ & $\begin{array}{l}\text { Categorical } \\
\text { None } \\
\text { Either } \\
\text { Both }\end{array}$ & Equipment & $\begin{array}{l}\text { Cost and skill investment in specialist goose hunting } \\
\text { equipment (e.g. goose decoys and/or calls). Potentially } \\
\text { increases success of each hunting day and hence larger } \\
\text { annual goose bags }\end{array}$ \\
\hline $\begin{array}{l}\text { When did you mostly go goose hunting in } \\
\text { 2013-2014? }\end{array}$ & $\begin{array}{l}\text { Categorical } \\
\text { It varies } \\
\text { Weekdays } \\
\text { Weekends/ } \\
\text { holidays } \\
\text { Every } \\
\text { opportunity }\end{array}$ & When & $\begin{array}{l}\text { If restricted by when can go hunting (e.g. weekends) lessens } \\
\text { hunting opportunities and hence smaller annual goose bags }\end{array}$ \\
\hline
\end{tabular}

${ }^{a}$ First level given for each categorical variable was set as the base comparative level

models, where number of goose hunting days was combined with each of the categorical predictors, (e.g. days + equipment). We ran these models individually to assess their impact and to test the effects of different hunter behavioural characteristics. We then combined all behavioural covariates to create a full model, as well as adding interactions between 'days' and 'distance' and 'days' and 'when'. Interactions were included as these two categorical predictors may potentially influence the number of hunting days, hence overall goose bag sizes. We then specified a series of behavioural candidate models with selected predictors removed to see if they improved or detracted from the full model. Data for all behavioural models were taken from 856 respondents who completed all selected behavioural questions. Model validation was applied to our optimal model following standard protocols, plotting Pearson residuals versus fitted values and for covariates to visualize and identify distinct patterns (Zuur et al. 2009). A second set of models was formulated to combine the best behavioural models with our selected motivational predictors. These models were formulated and selected following the same procedure as used for the behavioural models. These combined models used data from 756 respondents, as not all respondents completed the full set of selected motivational questions. This set of models included the two best behavioural models, without motivational 
Table 3 Survey questions considered as potential motivational predictor variables, as well as additional attitude questions analysed

\begin{tabular}{|c|c|c|c|}
\hline Survey question & $\begin{array}{l}\text { Response type and } \\
\text { modelled levels }{ }^{\mathrm{a}}\end{array}$ & Predictor variable & Comments and hypothesized impact \\
\hline $\begin{array}{l}\text { How important are the following } \\
\text { statements for you when you go } \\
\text { on hunting? }\end{array}$ & Categorical & & $\begin{array}{l}\text { Selected series of attitude statements about hunter } \\
\text { motivations for going goose hunting }\end{array}$ \\
\hline For the sake of the challenge & $\begin{array}{l}\text { Neutral }(3) \\
\text { Not important }(1,2) \\
\text { Important }(4,5)\end{array}$ & Challenge & $\begin{array}{l}\text { Agreement suggestive of greater motivation to go } \\
\text { goose hunting and potentially higher annual goose } \\
\text { bags }\end{array}$ \\
\hline $\begin{array}{l}\text { To manage and control the } \\
\text { number of geese }\end{array}$ & $\begin{array}{l}\text { Neutral }(3) \\
\text { Not important }(1,2) \\
\text { Important }(4,5)\end{array}$ & Control & $\begin{array}{l}\text { Agreement indicative of readiness to shoot more } \\
\text { geese, achieving higher annual goose bags }\end{array}$ \\
\hline For the meat & $\begin{array}{l}\text { Neutral }(3) \\
\text { Not important }(1,2) \\
\text { Important }(4,5)\end{array}$ & Meat & $\begin{array}{l}\text { Agreement suggestive of greater motivation for } \\
\text { goose hunting to provide meat, leading to larger } \\
\text { annual goose bags }\end{array}$ \\
\hline $\begin{array}{l}\text { To get peace and quiet from a } \\
\text { stressful everyday life }\end{array}$ & $\begin{array}{l}\text { Neutral }(3) \\
\text { Not important }(1,2) \\
\text { Important }(4,5)\end{array}$ & Peace & $\begin{array}{l}\text { Agreement suggestive of enjoyment of experience } \\
\text { rather than focusing on number of geese shot, } \\
\text { potentially resulting in lower annual goose bags }\end{array}$ \\
\hline $\begin{array}{l}\text { How many geese would you be } \\
\text { happy to shoot in a day's goose } \\
\text { hunt? }\end{array}$ & $\begin{array}{l}\text { Categorical } \\
0-2 \\
3-5 \\
6+\end{array}$ & Goal & $\begin{array}{l}\text { Preference for higher goose bags per hunting event, } \\
\text { hence higher annual goose bags }\end{array}$ \\
\hline $\begin{array}{l}\text { How important do you think it is } \\
\text { that hunting helps control the } \\
\text { size of large goose populations } \\
\text { in Denmark? }\end{array}$ & $\begin{array}{l}\text { Categorical } \\
\text { Neutral }(3) \\
\text { Not important }(1,2) \\
\text { Important }(4,5)\end{array}$ & & Not used in models to predict goose bag sizes \\
\hline $\begin{array}{l}\text { If the hunting season was opened } \\
\text { for more hunting of geese, how } \\
\text { much more are you willing to } \\
\text { shoot compared to your current } \\
\text { yield? }\end{array}$ & $\begin{array}{l}\text { Categorical } \\
10 \% \\
25 \% \\
50 \% \\
75 \% \\
100 \% \text { and more }\end{array}$ & & Not used in models to predict goose bag sizes. \\
\hline $\begin{array}{l}\text { How much are you willing to } \\
\text { reduce your current yield if the } \\
\text { hunt should be limited to protect } \\
\text { a falling goose population? }\end{array}$ & $\begin{array}{l}\text { Categorical } \\
10 \% \\
25 \% \\
50 \% \\
75 \% \\
\text { Stop completely }\end{array}$ & & Not used in models to predict goose bag sizes \\
\hline
\end{tabular}

${ }^{a}$ First level given for each categorical variable was set as the base comparative level, and numbers in brackets indicate score on 5 point Likert scale used for these survey questions $(1=$ not at all important to $5=$ extremely important $)$

predictors, for valid comparisons. We evaluated all models comparing Akaike's information criterion (AIC) and $\triangle \mathrm{AIC}$ values.

$\Delta_{i}=\mathrm{AIC}_{i}-\mathrm{AIC}_{\min }$, for $i=1,2, \ldots, R$.

We did not use a correction for AIC values (AICc), as AIC figures are known to converge with large sample sizes (Burnham et al. 2011). All analyses were done using statistical procedures available in R 3.3.0 (https://cran.r- project.org/) and using the MASS and ggplot2 packages (Venables and Ripley 2002; Wickham 2009).

\section{RESULTS}

\section{Respondent characteristics}

Virtually all respondents were male, with only four female respondents $(n=962)$. The average respondent age was 
52 years $(\mathrm{SD} \pm 14.55$, median $=53, \min -\max =18-86)$. For respondents indicating how long they had been goose hunting $(n=803)$, the average respondent was a long-time hunter having hunted geese for 16 years $(S D \pm 13.71$, $\min -\max =1-65$ ).

\section{Overall goose bag}

For the 2013 hunting season, approximately 56000 geese were shot by 9660 hunters who reported their hunting bags. The average hunter shot 6 geese in total $(\mathrm{SD} \pm 14.11)$, but bag size distribution was heavily positively skewed (median $=2$, min-max $=1-678)$. The majority $(52 \%)$ of goose hunters only shot one or two geese during the course of the hunting season, accounting for $13 \%$ of the overall goose bag. Over half the annual reported goose bag was shot by a very small proportion of goose hunters (12\%) (Fig. 1). Very similar patterns were seen for the 2014 and 2015 hunting seasons (Fig. S1, Appendix S2). The average hunter for this high bag group (11+ geese) shot 27 geese in total $(\mathrm{SD} \pm 33.64, \quad$ median $=18, \quad \min -\max =11-678)$. This analysis highlighted the impact of a small number of goose hunters on the overall annual goose bag.

\section{Annual goose hunting activity}

Of hunters that submitted goose bag reports in 2013 $(n=9660)$, a large proportion (46\%) did not go on to shoot geese in the following 2014 hunting season. However, there were considerable differences between goose bag groups. A very high portion of high bag hunters $(11+$ geese in 2013) went on to shoot geese in 2014 (80\%), as well as shooting geese in consecutive years (2014 and 2015). The majority (59\%) of low bag hunters (1-2 geese in 2013) did not shoot any geese in 2014, and 46\% did not shoot geese in either 2014 or 2015 (Fig. 2a and b). A binomial GLM showed there was a positive relationship between total

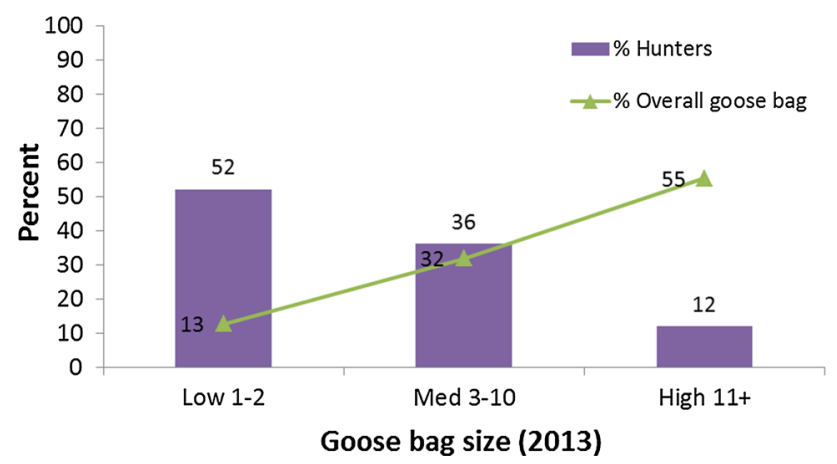

Fig. 1 Proportion of hunters having shot geese by bag group and proportion of overall goose bag shot by each bag group during the 2013 hunting season $(n=9660)$ goose bag sizes in 2013 and the probability of shooting geese in 2014 (Fig. 2c). For those hunters who shot geese in 2013 and then went on to do so in $2014(n=5219)$, the majority $(56 \%)$ remained in the same bag groups $(1-2$, $3-10$, or $11+$ ). The high bag group had the highest proportion not switching bag group (63\%). As total bag size increased, the probability of staying in the same bag group increased, as indicated by a binomial GLM (Fig. 2d).

\section{Effect of goose hunting days}

Obtained from survey data, the median total number of goose hunting days for survey respondents was 12 $(n=905)$, with the distribution positively skewed (min$\max =1-110$, excluding outliers). A negative binomial GLM showed there was evidence for a positive relationship between the number of goose hunting days (as the only predictor) and total goose bags $(b=0.02, z=10.08$, $p<0.001$ ) (Fig. 3a). However, this single predictor variable only explained $10.5 \%$ of goose bag variance, suggesting that other factors may contribute to and predict goose bag sizes. Some respondents achieved high goose bags over several days (e.g. one respondent shot 27 geese in 4 days), whilst other respondents indicated many goose hunting days but achieved relatively low goose bags. These were all considered feasible outcomes but raised questions about (1) why some respondents appeared to be more successful; (2) whether some respondents were actually goose hunting each time?

\section{Effects of hunter characteristics}

\section{Behavioural predictors}

The optimal behavioural model was found to be one which included all selected behavioural predictors, as well as specified interactions. This model $\quad(\mathrm{AIC}=5638.5$; Table 4), explaining $30.7 \%$ of goose bag variance (parameter estimates in Table S1, Appendix S2). Other candidate models with single and combinations of behavioural predictors did not improve model fits. $\triangle$ AIC values were considerably larger than those needed to support them as plausible competing models, $\triangle \mathrm{AIC}<14$ (Burnham et al. 2011). Comparing AIC values for these candidate models (Table 4) indicated that the three most influential behavioural predictors when individually combined with 'days' were (1) having access to multiple hunting 'areas' $(\mathrm{AIC}=5727.7)$; (2) use of 'specialist equipment' (AIC = 5777.6) and (3) 'checking' for geese in hunting areas $($ AIC $=5781.3)$. These three predictors all had positive effects on bag sizes. We visualized predicted values for these categorical levels in models including number of goose hunting days (Fig. 3b-d). Full set of plotted 
(a)

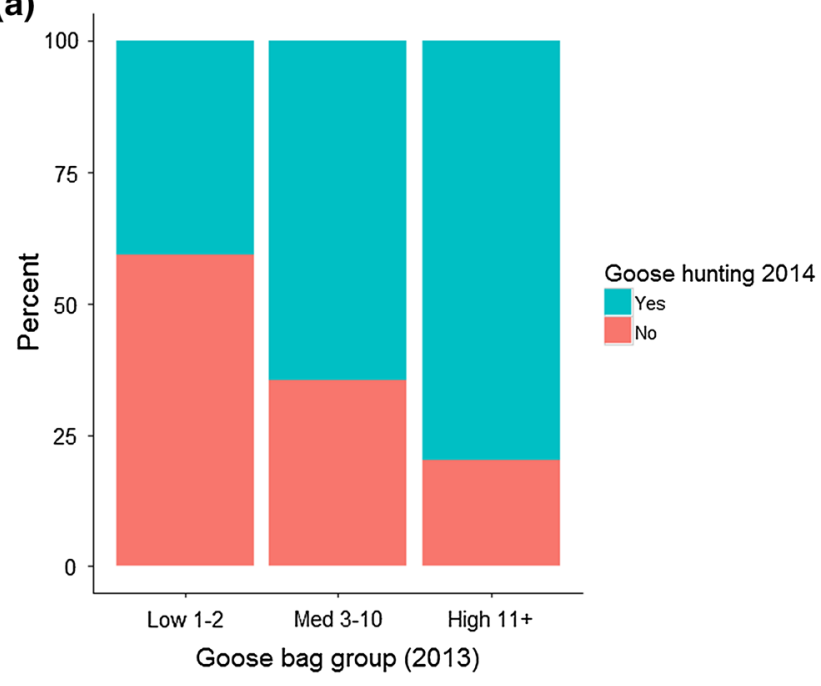

(c)

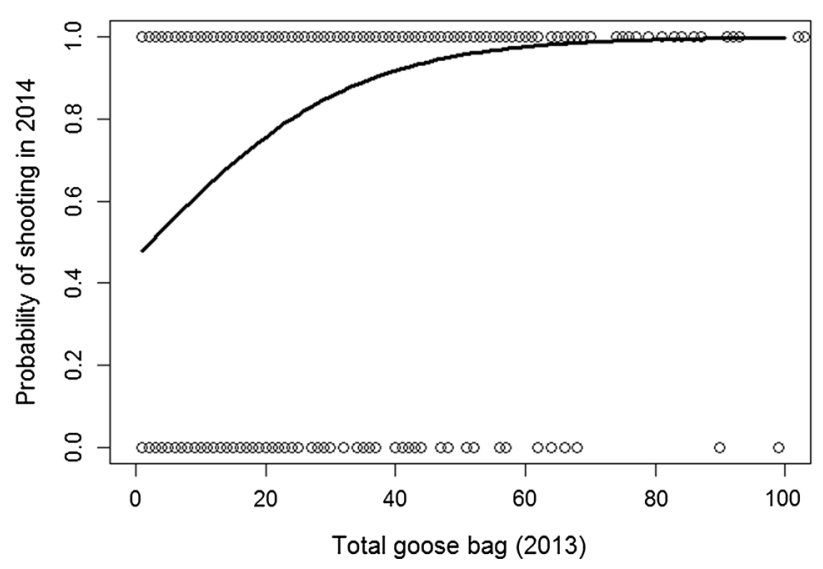

(b)

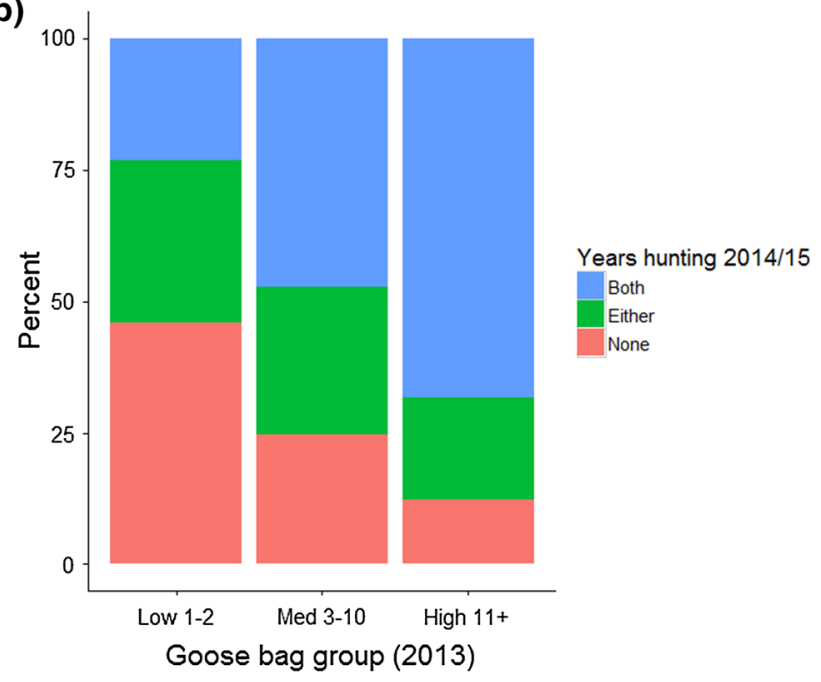

(d)

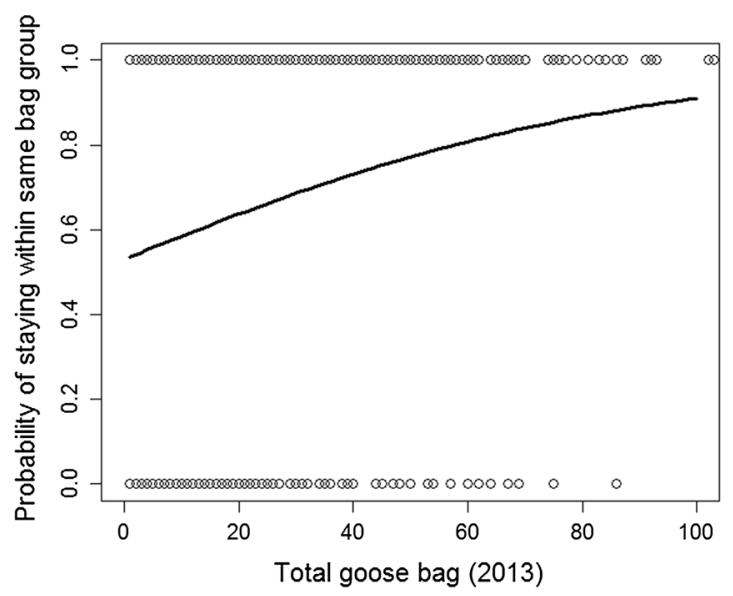

Fig. 2 Goose hunting activity for 2014-2015 for all hunters who submitted goose bags in 2013 ( $n=9660$ ): a proportion of respondents who went on to shoot geese in 2014; b proportion of respondents who shot geese in consecutive years for the 2014 and 2015 hunting seasons; c predicted values (solid line) for binomial GLM representing probability of shooting in geese in subsequent 2014 hunting season. For each unit increase in bag size ( 1 goose), there would be an expected 7\% increase in the odds of shooting geese in $2014\left(X_{1}^{2}=429.57, p<0.001\right.$, odds ratio $=1.066$ ); $\mathbf{d}$ predicted values (solid line) for binomial GLM representing probability of hunters shooting geese staying in the same bag group in subsequent 2014 hunting season. For each unit increase in the bag size, there would be an expected $2 \%$ increase in the odds of staying in the same bag group $\left(X_{1}^{2}=67.94, p<0.001\right.$, odds ratio $\left.=1.022\right)$. Dots in $\mathbf{c}$ and $\mathbf{d}$ are observed values

predicted values for all behavioural variables are provided in Fig. S2, Appendix S2.

\section{Motivational predictors}

Adding all motivational predictors to the full behavioural model without interactions (AIC $=5054.4)$ improved this model (AIC $=4948.2)$, based on comparative AIC values (Table S2, Appendix S2). Further model tests showed that the motivational predictors 'meat' and 'peace' were not statistically significant, whilst the predictor 'challenge' was only marginally significant $(p<0.1)$. Our analyses indicated that the two most influential motivational predictors were (1) whether respondents considered their hunting activity important for managing and controlling goose populations, or (2) whether they were motivated to shoot a high number of geese each hunting event (Fig. S3, Appendix S2). Adding these two predictors to the optimal behavioural model, including interactions, gave the lowest AIC value $(\mathrm{AIC}=4935.5)$, explaining $38.9 \%$ of goose bag variance. Although motivational characteristics are indicative of higher goose bags, most respondents (71\%) were satisfied with only shooting $0-2$ geese each time; a much smaller proportion (6\%) desired $6+$. Furthermore, most respondents $(59 \%)$ also indicated managing geese was not an important motivational factor to go hunting, with only $10 \%$ indicating it was important. 

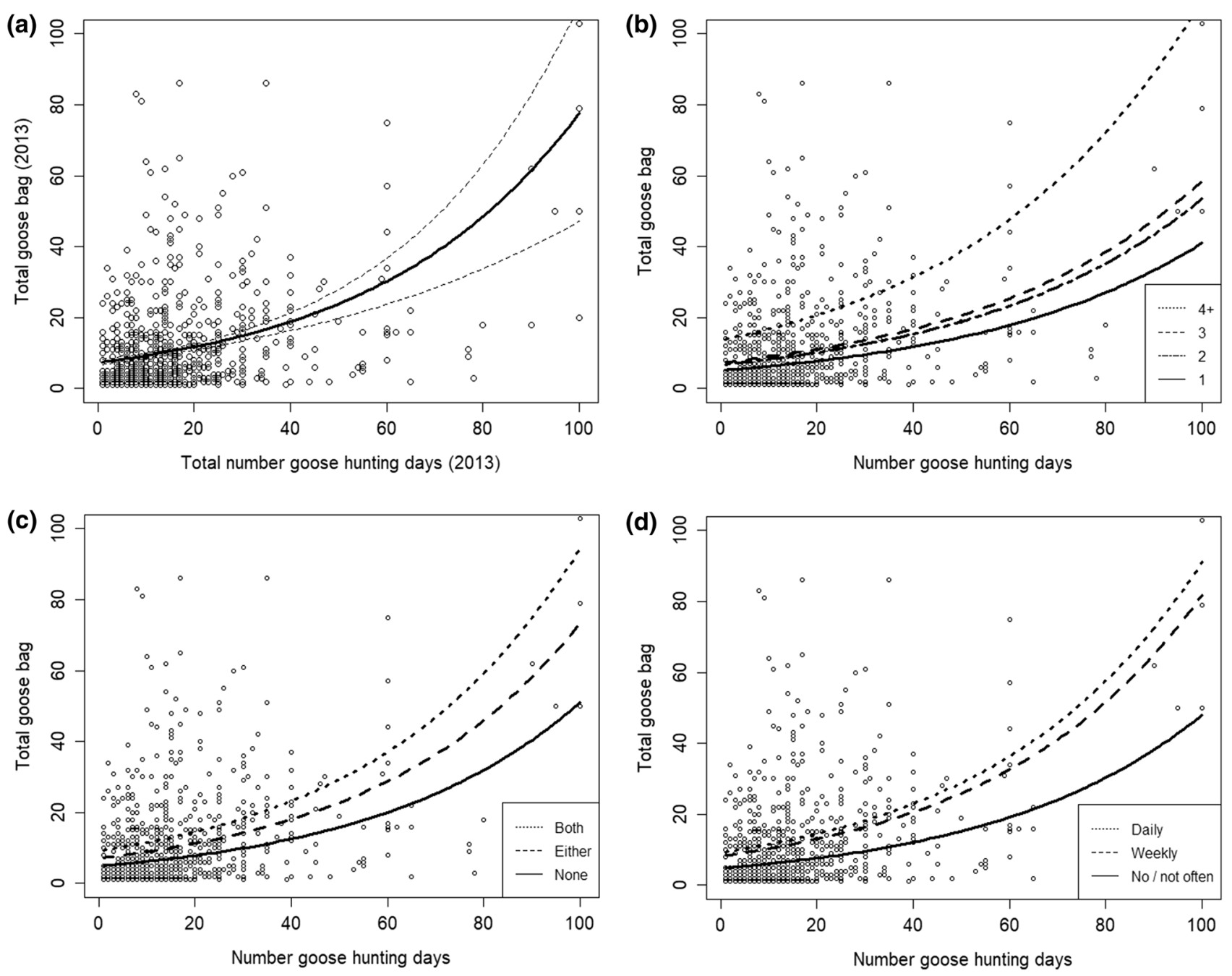

Fig. 3 Observed respondent goose bags (dots) plotted against total number of goose hunting days. Plots show the combined effect of increasing goose hunting days, as well as the combined effect with each behavioural categorical predictor: a predicted values from the negative binomial model for the single variable 'days' have been added as a solid line, with dotted lines showing 95\% confidence intervals. Predicted values for 3 best behavioural categorical predictors and levels are shown with lines as indicated: $\mathbf{b}$ days + areas; $\mathbf{c}$ days + equipment; $\mathbf{d}$ days + check

\section{Other hunting activity}

Analysis of survey respondents' 2013 hunting bag records showed that the average respondent shot several huntable species other than geese (mean $=7, \mathrm{SD} \pm 3.94$, median $=6$, $\min -\max =1-22$ ), but there were differences between goose bag groups (Fig. 4a). The average respondent's overall non-goose bag for 2013 was 65 individuals (SD \pm 107.35 ), but the non-goose bag distribution was positively skewed $($ median $=30, \quad \min -\max =0-1181)$. Comparing respondent groups showed that those with a higher goose bags shot a greater variety of species and shot many more individuals (Fig. 4a and b). Further analysis of the number of individuals shot within species groupings showed that there were slight differences between respondent groups in the composition of their hunting bags
(Fig. 4c). It is evident that most respondents did not just shoot geese and had much broader hunting interests.

\section{Managing geese and willingness to alter hunting activity}

The majority (62\%) of respondents indicated that they considered hunting an important tool to control the size of large goose populations. A higher proportion of respondents $(73 \%)$ in the high bag group considered hunting an important tool in comparison to the other bag groups. Using Pearson's Chi-square test showed this was a significant association, but Cramér's $V$ test indicated it was weak $\left(X^{2}=26.02, \quad p>0.05, \quad\right.$ d.f. $\left.=4, \quad \phi c=0.1\right) . \quad 62 \% \quad$ of respondents indicated that they would only be willing to increase the number of geese they shot by 10 or $25 \%$, in 
Table 4 AIC values for all formulated behavioural models $(n=856)$

\begin{tabular}{|c|c|c|c|}
\hline Models & AIC & $\Delta \mathrm{AIC}$ & $\overline{\operatorname{ED}^{\mathrm{a}}(\%)}$ \\
\hline Days + area + check + distance + dog + equipment + when + days $\times$ distance + days $\times$ when & 5638.5 & 0 & 30.7 \\
\hline Days + area + check + distance + dog + equipment + when & 5657.9 & 19.4 & 28.2 \\
\hline Days + area + check + distance + equipment + when (minus dog) & 5658.5 & 25 & 28.0 \\
\hline Days + area + check + dog + equipment + when (minus distance) & 5664.7 & 26.2 & 27.1 \\
\hline Days + area + check + distance + dog + equipment (minus when) & 5672.4 & 33.9 & 26.5 \\
\hline Days + area + check + equipment (minus distance, dog and when) & 5685.5 & 52 & 24.7 \\
\hline Days + areas + distance + when (minus check, dog and equipment) & 5697.6 & 64.1 & 24.1 \\
\hline Days + areas & 5727.7 & 94.2 & 20.4 \\
\hline Days + check + dog + equipment & 5740.1 & 101.6 & 19.6 \\
\hline Days + equipment & 5777.6 & 144.1 & 15.7 \\
\hline Days + check & 5781.3 & 147.8 & 15.3 \\
\hline Days + when & 5796.6 & 163.1 & 14.1 \\
\hline Days + dog & 5813.2 & 174.7 & 12.1 \\
\hline Days + distance & 5816 & 182.5 & 12.2 \\
\hline Areas & 5816.7 & 183.2 & 12.0 \\
\hline Days & 5827.5 & 194 & 10.5 \\
\hline Equipment & 5886.2 & 252.7 & 4.9 \\
\hline Check & 5887.5 & 254 & 4.7 \\
\hline When & 5891.7 & 258.2 & 4.5 \\
\hline Distance & 5919.6 & 281.1 & 1.6 \\
\hline Dog & 5920.3 & 281.8 & 1.1 \\
\hline
\end{tabular}

${ }^{a}$ Explained deviance

comparison to their current goose bag. Using Pearson's Chi-square test showed there was no significant association between respondent bag groups and their willingness to shoot more geese $\left(X^{2}=7.99, p>0.05\right.$, d.f. = 4) (Fig. 5a). Using the 2013 bag size for each respondent and the percentage increase they indicated, we calculated an overall $35 \%$ uplift in the annual goose bag, if respondents were requested to shoot more. In order to protect a declining goose population, $25 \%$ of all respondents would be willing to totally stop, whilst a further $28 \%$ would be willing to reduce their goose bag by at least $75 \%$. A Pearson's Chisquare test showed there was a significant association between respondent bag groups and their willingness to shoot less geese $\left(X^{2}=11.31, p<0.05\right.$, d.f. $\left.=4\right)$; however, Cramér's $V$ indicated this association was weak $(\phi c=0.1)$ (Fig. 5b). Based on each respondent's 2013 bag size and the percentage decrease they indicated, we calculated an overall $43 \%$ reduction in the annual goose bag, if respondents were requested to shoot less.

\section{DISCUSSION}

Our study has shown that the majority of Danish hunters that shot geese did so only on a casual basis. Most hunters tended to shoot just one or two geese during the course of a hunting season and were less likely to shoot geese every year. These low bag hunters only had a small impact on the number of geese shot, whilst the majority of geese were shot by a comparatively small proportion of hunters. The focus of the ISMP for the pink-footed goose was initially on increasing harvests, as the size of the population continued to grow. This guided our interest in determining what characteristics enabled some hunters to achieve higher goose bags. We have shown there is a positive relationship between the number of hunting days and bag size. This echoes findings of a study amongst duck hunters in the US (Haugen et al. 2015), but our data also showed considerable variation. Some respondents achieved high goose bags whilst indicating these were shot over just a few hunting days. Unlike the US, Denmark has no daily bag limits. Our analyses did indicate that 3 behavioural characteristics may enhance the success of hunting when a hunter does go out hunting, leading to higher bag sizes: access to multiple hunting areas, using specialist equipment (e.g. decoys and/or goose calls) and actively checking for geese prior to hunting. These characteristics indicate that investment and commitment is needed to be an effective goose hunter. Waterbird hunting is known for its high degree of specialization, in comparison to other hunting 

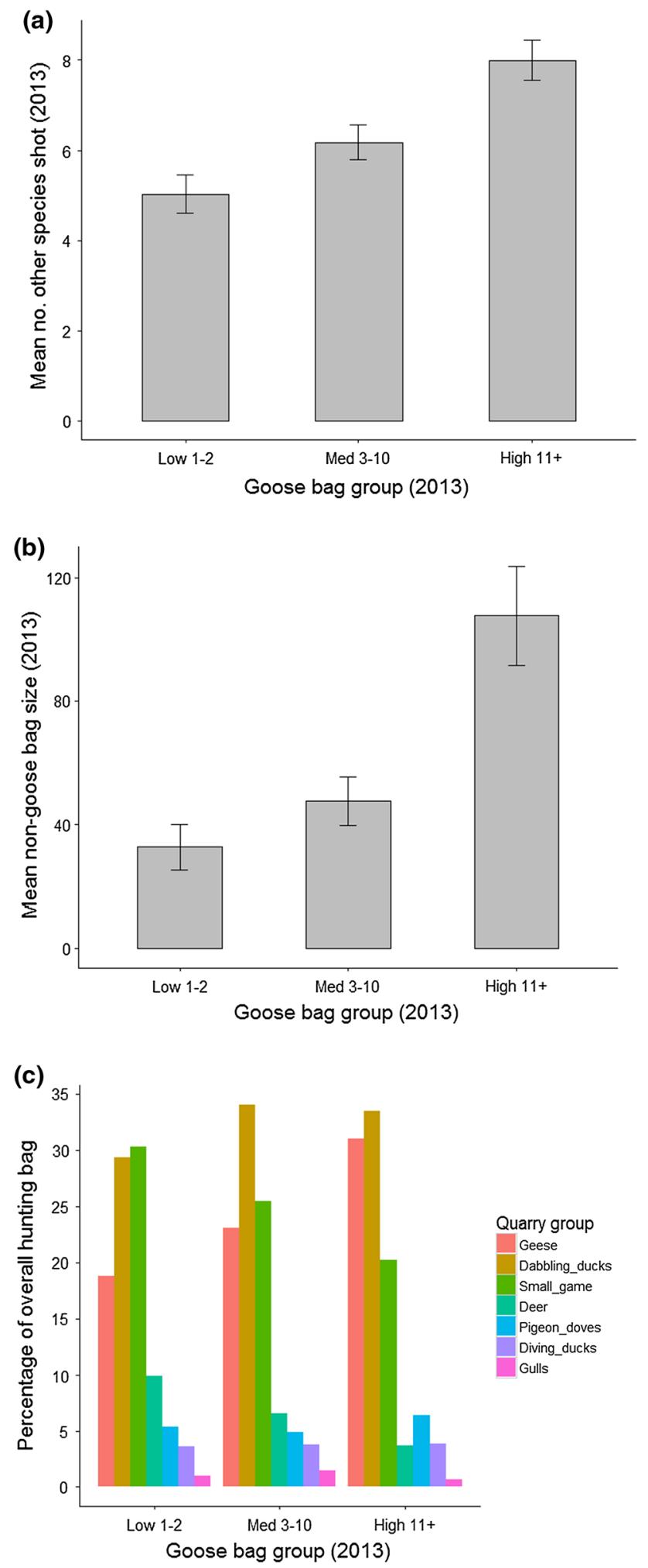

Fig. 4 Other huntable species shot by survey respondents $(n=905)$ in 2013: a mean number of non-goose species shot by respondent groups, $\mathbf{b}$ mean number of non-goose individuals shot by respondent groups, $\mathbf{c}$ proportion of overall hunting bag for individuals shot within species groupings, by respondent group types (Miller and Graefe 2000). For wildlife managers endeavouring to manage rapidly growing goose populations, specialization and use of hunting as a management tool has many implications. Our study has provided useful insights regarding three broad aspects that are particularly relevant where recreational hunting is to be employed and increased harvest rates required (1) the ability and effectiveness of recreational hunters to attain required harvest bags, (2) their willingness to alter their hunting activity and (3) act as responsible stewards, i.e. undertaking actions specifically to care for a valued resource (Bruskotter and Fulton 2012).

Certainly higher harvests can be attained using regulatory mechanisms such as extending hunting seasons. Where this has been shown to be the case (Madsen et al. 2016), it was not known whether any particular group of hunters contributed more than others to the increased harvest (e.g. was it new entrants, a general increase in individual bag sizes or a small group of hunters shooting many more)? As the majority of hunters, in our study, were casually involved in goose hunting, would they have sufficient access, knowledge and skills to hunt geese effectively and increase overall goose harvests? We have shown that attaining higher goose bags requires a degree of specialization. Specialization is viewed as progressive development over time from novice to expert (Scott and Shafer 2001; Kuentzel and Heberlein 2006). It has also been shown that participation in hunting can decrease if there are constraints (e.g. limited access to hunting areas or needing specialist equipment) (Barro and Manfredo 1996). Devoting the time, gaining access (hunting rights) and the purchase of specialist equipment may pose considerable barriers for casual hunters or new entrants. These factors may impede attaining the necessary proficiency in goose hunting and the ability of these hunters to increase their harvests without detrimental consequences (e.g. wounding). This latter point has significance for societal acceptance if recreational hunting is to be used to manage wildlife populations, such as geese.

The majority of respondents in our study agreed that hunting has an important role in managing goose populations. Furthermore, our study has shown that most hunters would be willing to increase, as well as decrease their hunting effort, potentially leading to large changes in overall annual goose harvests. However, our results, somewhat surprisingly, indicated that motivational factors did not have much influence in determining goose bag sizes. This seems to reflect that motivations to go hunting span a variety of experience preferences (Schroeder et al. 2006; Harper et al. 2012), rather than purely consumptive motives that have often been associated with hunters in the past (Wam et al. 2013). We have shown that most respondents were less focused on achieving high daily 
(a)

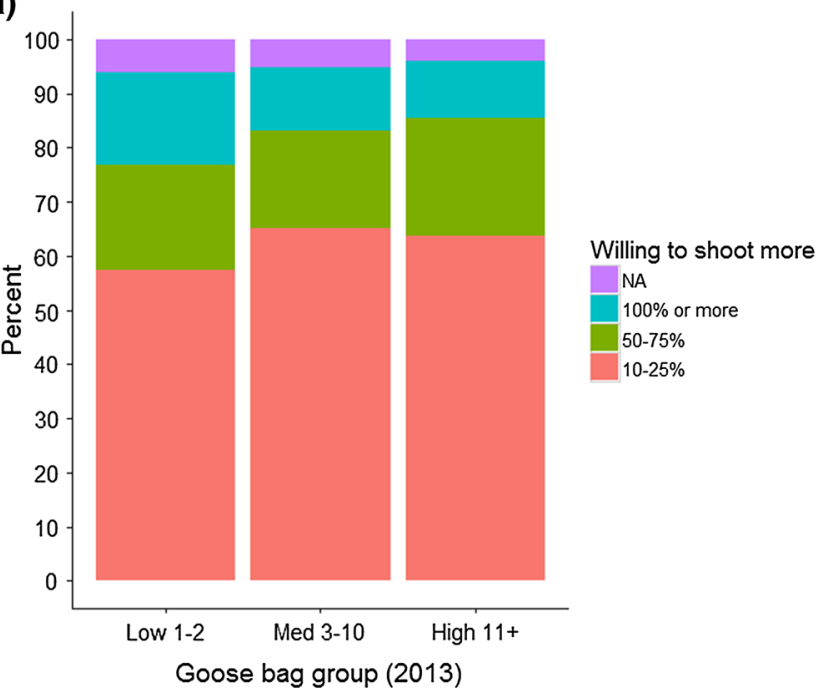

(b)

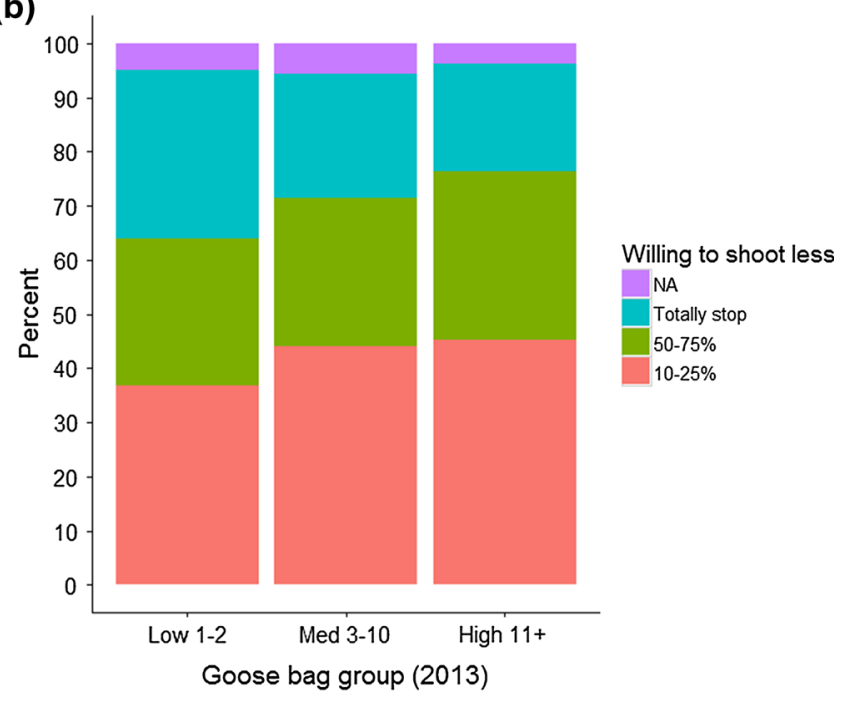

Fig. 5 Proportion of respondents willing to alter how many geese they shoot from current goose bag sizes $(n=905)$ : a willingness to increase goose bag if hunting of geese was opened and freely permitted; $\mathbf{b}$ willingness to reduce goose bag if hunting of geese was restricted to protect a falling goose population

goose bags and likely to be satisfied by shooting, at most, a couple of geese each time they hunted. For the majority of respondents, managing geese was not an important motivational factor to go goose hunting. Furthermore, respondents in our study had broad hunting interests and were not solely focused on shooting geese but participated in several forms of hunting (e.g. duck, small game and deer). These findings suggest that, although respondents indicated their willingness to alter their goose hunting effort, personal circumstances, hunting preferences as well as other external factors may mitigate these intentions. It has been shown that social pressures and the perceived ease or difficulty of performing a behaviour can have a significate effect on intentions in specific hunting contexts (hunting species limited in time and place) (Hrubes et al. 2001; Shrestha et al. 2012). Hence, constraints perceived by hunters (e.g. access to quality hunting areas or lacking specialized hunting skills/equipment) may hinder future participation.

There are potential risks and unintended consequences of actively promoting and pursuing higher harvests, such as the wounding of geese. This may be related to increased exposure to less experienced or new goose hunters. This has implications for wildlife managers and hunting organizations, if recreational hunting is to be employed as a management tool. Increasingly, as society changes (e.g. urbanization) and values shift (e.g. towards a mutualist orientation), hunting comes under greater scrutiny from animal ethics points of view and sections of society hold more negative attitudes towards hunting (Gamborg and Jensen 2017). This was a noted ethical concern for the ISMP of the pink-footed goose (Madsen et al. 2017). Mitigating measures can be successfully employed to minimize wounding, for example hunter education, skill development and promoting beneficial hunting practices (e.g. use of decoys and goose calls) (Noer et al. 2007). There is evidence of an increase in the efficiency amongst Danish goose hunters, as wounding has declined despite increasing harvests (Clausen et al. 2017). Our study has indicated that specialization is associated with more effective goose hunting practices and this may have been a major contributor to the decline. Thus, it would seem if hunting is to be successfully employed as a management tool, wildlife managers and hunting organizations need to consider facilitating the development of skills and beneficial practices amongst targeted groups of recreational hunters. Hunters are themselves increasingly recognizing the multi-functionality of their recreational pastime and hunting ethics continue to evolve with hunters self-imposing socially, aesthetically and morally defensible ways of hunting (Kaltenborn et al. 2013; Gamborg et al. 2017; von Essen 2018). Consideration should be given to how best to promote and instil suitable hunting practices as higher social standards dictate why, how and in what circumstances particular hunting practices are acceptable to manage wildlife populations.

\section{CONCLUSIONS}

The use of recreational hunters to manage wildlife populations raises many practical challenges and ethical issues for wildlife managers. There is growing recognition that human components and societal values need to be explicitly accounted for in adaptive management (Enck et al. 2006; 
Johnson et al. 2015; Schroeder et al. 2017). Our study was focused on the management of a rapidly increasing goose population and the potential of recreational hunters to achieve management goals that are both ecologically and socially desirable. We have identified several behavioural characteristics that typify effective goose hunting practices, suggesting a degree of specialization is necessary to increase goose harvests, as well as mitigating animal welfare issues (e.g. wounding). Our study also suggests that most goose hunters, although recreational, do consider they have stewardship role and would be willing to adjust their hunting effort. However, in our study most hunters only shot one or two geese, and not every year, and had a limited impact on overall goose harvests. The challenge for wildlife managers is to engage and influence such a relatively large section of the hunting community as part of an adaptive harvest management regime. This is important, if hunters interest in one form of hunting (e.g. goose hunting) is casual, and their hunting preferences, circumstances and perceived constraints hinder or conflict with the achievement with management objectives. If recreational hunters are to be used as a management tool, wildlife managers and hunting organizations will need to consider how best to facilitate skill development, hunting practices and socially legitimate hunting ethics to foster the stewardship role of hunting. We conclude that it is incumbent on wildlife managers to recognize and deal with the internal factors (e.g. skill development and hunter satisfaction) and external influences (e.g. animal welfare concerns) to alleviate potential tensions in the multi-functionality of hunting as a legitimate and accepted recreational past-time and management tool.

Acknowledgements $\mathrm{We}$ are indebted and very grateful to all the Danish goose hunters who participated in our study. This research received funding from Aarhus University and 15 Juni Fonden (project Forbedret Gåsejagt). We are also grateful to two anonymous reviewers for their constructive comments that helped improve our manuscript.

Open Access This article is distributed under the terms of the Creative Commons Attribution 4.0 International License (http:// creativecommons.org/licenses/by/4.0/), which permits unrestricted use, distribution, and reproduction in any medium, provided you give appropriate credit to the original author(s) and the source, provide a link to the Creative Commons license, and indicate if changes were made.

\section{REFERENCES}

Asferg, T. 2016. Indberetning af vildtudbytte for jagtsæsonen 2014/15: første sæson med reglen om "vildtudbytte før jagttegn”. In ed. DCE. Aarhus: Aarhus University.
Barro, S.C., and M.J. Manfredo. 1996. Constraints, psychological investment, and hunting participation: Development and testing of a model. Human Dimensions of Wildlife 1: 42-61.

Bradbeer, D.R., C. Rosenquist, T.K. Christensen, and A.D. Fox. 2017. Crowded skies: Conflicts between expanding goose populations and aviation safety. Ambio 46: 290-300. https://doi.org/10.1007/ s13280-017-0901-2.

Bruskotter, J.T., and D.C. Fulton. 2012. Will hunters steward wolves? A comment on Treves and Martin. Society \& Natural Resources 25: $97-102$.

Burnham, K.P., D.R. Anderson, and K.P. Huyvaert. 2011. AIC model selection and multimodel inference in behavioral ecology: Some background, observations, and comparisons. Behavioral Ecology and Sociobiology 65: 23-35.

Clausen, K.K., T.E. Holm, L. Haugaard, and J. Madsen. 2017. Crippling ratio: A novel approach to assess hunting-induced wounding of wild animals. Ecological Indicators 80: 242-246.

Decker, D.J., and N.A. Connelly. 1989. Motivations for deer hunting: Implications for antlerless deer harvest as a management tool. Wildlife Society Bulletin 1973-2006: 455-463.

Enck, J.W., D.J. Decker, S.J. Riley, J.F. Organ, L.H. Carpenter, and W.F. Siemer. 2006. Integrating ecological and human dimensions in adaptive management of wildlife-related impacts. Wildlife Society Bulletin 34: 698-705.

Fischer, A., V. Kereži, B. Arroyo, M. Mateos-Delibes, D. Tadie, A. Lowassa, O. Krange, and K. Skogen. 2013a. (De)legitimising hunting-Discourses over the morality of hunting in Europe and eastern Africa. Land Use Policy 32: 261-270.

Fischer, A., C. Sandström, M. Delibes-Mateos, B. Arroyo, D. Tadie, D. Randall, F. Hailu, A. Lowassa, et al. 2013b. On the multifunctionality of hunting-An institutional analysis of eight cases from Europe and Africa. Journal of Environmental Planning and Management 56: 531-552.

Fox, A.D., and J. Madsen. 2017. Threatened species to superabundance: The unexpected international implications of successful goose conservation. Ambio 46: 179-187. https://doi.org/ 10.1007/s13280-016-0878-2.

Gamborg, C., and F.S. Jensen. 2017. Attitudes towards recreational hunting: A quantitative survey of the general public in Denmark. Journal of Outdoor Recreation and Tourism 17: 20-28.

Gamborg, C., F.S. Jensen, and P. Sandøe. 2017. Killing animals for recreation? A quantitative study of hunters' motives and their perceived moral relevance. Society \& Natural Resources: 1-14.

Hansen, H.P. 2000. Jagt I Danmark År 2000 (Hunting in Denmark in the year 2000). Roskilde.

Harper, C.A., C.E. Shaw, J.M. Fly, and J.T. Beaver. 2012. Attitudes and motivations of Tennessee deer hunters toward quality deer management. Wildlife Society Bulletin 36: 277-285.

Haugen, M.T., L.A. Powell, M.P. Vrtiska, and K.L. Pope. 2015. The effects of harvest regulations on behaviors of duck hunters. Human Dimensions of Wildlife 20: 15-29.

Hrubes, D., I. Ajzen, and J. Daigle. 2001. Predicting hunting intentions and behavior: An application of the theory of planned behavior. Leisure Sciences 23: 165-178.

Jensen, G.H., J. Madsen, and I.M. Tombre. 2016. Hunting migratory geese: Is there an optimal practice? Wildlife Biology 22: 194-203.

Johnson, F.A., G.S. Boomer, B.K. Williams, J.D. Nichols, and D.J. Case. 2015. Multilevel learning in the adaptive management of waterfowl harvests: 20 years and counting. Wildlife Society Bulletin 39: 9-19.

Kaltenborn, B.P., O. Andersen, J. Vitterso, and T.K. Bjerke. 2012. Attitudes of Norwegian ptarmigan hunters towards hunting goals and harvest regulations: The effects of environmental orientation. Biodiversity and Conservation 21: 3369-3384. 
Kaltenborn, B.P., O. Andersen, and J.D.C. Linnell. 2013. Predators, stewards, or sportsmen-How do Norwegian hunters perceive their role in carnivore management? International Journal of Biodiversity Science, Ecosystem Services \& Management 9: 239-248.

Kuentzel, W.F., and T.A. Heberlein. 2006. From novice to expert? A panel study of specialization progression and change. Journal of Leisure Research 38: 496-512.

Lundhede, T.H., J.B. Jacobsen, and B.J. Thorsen. 2015. A hedonic analysis of the complex hunting experience. Journal of Forest Economics 21: 51-66.

Madsen, J., and J.H. Williams. 2012. International species management plan for the svalbard population of the pink-footed goose Anser brachyrhynchus. Bonn, Germany.

Madsen, J., K.K. Clausen, T.K. Christensen, and F.A. Johnson. 2016. Regulation of the hunting season as a tool for adaptive harvest management-first results for pink-footed geese Anser brachyrhynchus. Wildlife Biology 22: 204-208.

Madsen, J., J.H. Williams, F.A. Johnson, I.M. Tombre, S. Dereliev, and E. Kuijken. 2017. Implementation of the first adaptive management plan for a European migratory waterbird population: The case of the Svalbard pink-footed goose Anser brachyrhynchus. Ambio 46: 275-289. https://doi.org/10.1007/ s13280-016-0888-0.

McKenzie, R., and J.M. Shaw. 2017. Reconciling competing values placed upon goose populations: The evolution of and experiences from the Islay Sustainable Goose Management Strategy. Ambio 46: 198-209. https://doi.org/10.1007/s13280-016-0880-8.

Miller, C.A., and A.R. Graefe. 2000. Degree and range of specialization across related hunting activities. Leisure Sciences 22: 195-204.

Noer, H., J. Madsen, and P. Hartmann. 2007. Reducing wounding of game by shotgun hunting: Effects of a Danish action plan on pink-footed geese. Journal of Applied Ecology 44: 653-662.

Primdahl, J., M. Bojesen, J.P. Vesterager, and L.S. Kristensen. 2012. Hunting and landscape in Denmark: Farmers' management of hunting rights and landscape changes. Landscape Research 37: 659-672.

Radder, L., and T. Bech-Larsen. 2008. Hunters' motivations and values: A South African perspective. Human Dimensions of Wildlife 13: 252-262.

Schroeder, S.A., D.C. Fulton, and J.S. Lawrence. 2006. Managing for preferred hunting experiences: A typology of Minnesota waterfowl hunters. Wildlife Society Bulletin 34: 380-387.

Schroeder, S.A., D.C. Fulton, J.S. Lawrence, and S.D. Cordts. 2017. How hunter perceptions of wildlife regulations, agency trust, and satisfaction affect attitudes about duck bag limits. Human Dimensions of Wildlife: 1-22.

Scott, D., and C.S. Shafer. 2001. Recreational specialization: A critical look at the construct. Journal of Leisure Research 33: 319-343.

Shrestha, S.K., R.C. Burns, C.D. Pierskalla, and S. Selin. 2012. Predicting deer hunting intentions using the theory of planned behavior: A survey of Oregon big game hunters. Human Dimensions of Wildlife 17: 129-140.

Stroud, D.A., J. Madsen, and A.D. Fox. 2017. Key actions towards the sustainable management of European geese. Ambio 46: 328-338. https://doi.org/10.1007/s13280-017-0903-0.

Venables, W.N., and B.D. Ripley. 2002. Modern applied statistics with $S$, 4th ed. New York: Springer. von Essen, E. 2018. The impact of modernization on hunting ethics: Emerging taboos among contemporary Swedish hunters. Human Dimensions of Wildlife 23: 21-38.

Wam, H.K., O. Andersen, and H. Chr. Pedersen. 2013. Grouse hunting regulations and hunter typologies in Norway. Human Dimensions of Wildlife 18: 45-57.

Wickham, H. 2009. ggplot2: Elegant graphics for data analysis. New York: Springer.

Zuur, A.F., E.N. Ieno, N.J. Walker, A.A. Saveliev, and G.M. Smith. 2009. Mixed effects models and extensions in ecology with $R$. New York: Springer.

\section{AUTHOR BIOGRAPHIES}

James Henty Williams $(\square)$ is a social science researcher at Aarhus University, Denmark. His areas of interest include multi-criteria decision-making and governance processes for natural resource management, with a particular focus on adaptive management, stakeholder engagement and social learning. He was part of the Coordination Unit for the AEWA International Species Management Plan for the Svalbard Pink-footed Goose.

Address: Department of Bioscience, Aarhus University, Kalø, Grenavej 14, 8410 Rønde, Denmark.

e-mail: jhw@bios.au.dk

Thorsten J. S. Balsby is a senior researcher at Aarhus University, Department of Bioscience, Wildlife Ecology. His research interests include statistics, ornithology and population ecology.

Address: Department of Bioscience, Aarhus University, Kalø, Grenavej 14, 8410 Rønde, Denmark.

e-mail: thba@bios.au.dk

Helle Ørsted Nielsen is a senior social science researcher at the Department of Environmental Science, Aarhus University. Her research interests concern the effectiveness of environmental policies and decision-making theory, applying a behavioural theory perspective.

Address: Aarhus University, Bartholins Alle 7, 8000 Aarhus C, Denmark.

e-mail: hon@ps.au.dk

Tommy Asferg is an emeritus senior biologist at the Section for Wildlife Ecology, Department of Bioscience, Kalø, Aarhus University. He has been responsible for the maintenance and analysis of the Danish hunting bag statistics for more than 40 years. His primary research focus is on the biology of Danish mammal species.

Address: Department of Bioscience, Aarhus University, Kalø, Grenavej 14, 8410 Rønde, Denmark.

e-mail: ta@bios.au.dk

Jesper Madsen is a professor at Aarhus University, Denmark, with an extensive experience with studies of human use of nature and its consequences for waterbird behaviour, site use and population dynamics. He is the head of the AEWA European Goose Management Platform Data Centre and chair of the Waterbird Harvest Specialist Group of Wetlands International.

Address: Department of Bioscience, Aarhus University, Kalø, Grenavej 14, 8410 Rønde, Denmark.

e-mail: jm@bios.au.dk 